\title{
Ameliorating effects of probiotics on alterations in iron homeostasis and inflammation in COVID-19
}

\author{
Eman M. El-Sayed ${ }^{1}\left[\right.$ (D) Khadiga S. Ibrahim² ${ }^{\mathbb{C}}$
}

Received: 31 August 2021 / Accepted: 3 February 2022 / Published online: 15 February 2022

(c) The Author(s), under exclusive licence to Springer Nature B.V. 2022

\begin{abstract}
Introduction The coronavirus disease (COVID-19) is caused by the severe acute syndrome coronavirus-2 (SARS-COV-2) and still threatens human life. This pandemic is still causing increased mortality throughout the world. Many recent studies have been conducted to discover the pathophysiology of this virus.

Material and methods However, in this narrative review, we attempted to summarize some of the alterations in physiological pathways that were evident in this viral invasion. Excessive inflammation that progresses to cytokine storm, changes in humoral and cell-mediated immunity, and observed alterations in iron metabolism are included in the pathogenesis of the virus. Iron homeostasis disturbances may persist for more than two months after the onset of COVID-19, which may lead to reduced iron bioavailability, hypoferremia, hyperferritinemia, impaired hemoglobin, and red blood cell synthesis. Furthermore, hypoferriemia may impair immune system function. Until now, the traditional treatments discovered are still being tried.

Results However, using probiotics as an adjuvant was shown to have beneficial effects on both iron homeostasis and immunity in COVID-19. Herein, we discussed the possible mechanisms achieved by probiotics to ameliorate iron and immunity changes based on the available literature.

Conclusion We concluded that supplementing probiotics with conventional therapy may improve COVID-19 symptoms and outcomes. Taking into consideration the use of good quality probiotics and appropriate dosage, undesirable effects can be avoided.
\end{abstract}

Keywords COVID-19 $\cdot$ Inflammation · Immunity $\cdot$ Iron $\cdot$ Probiotics

\section{Introduction}

The coronavirus disease 2019 (COVID-19) is a disease that is rapidly spreading throughout the world. The disease's clinical spectrum ranges from asymptomatic cases, mild, flu symptoms to pneumonia, and potentially fatal complications like acute respiratory distress syndrome (ARDS) and

Khadiga S. Ibrahim

khadigasalah@yahoo.com

Eman M. El-Sayed

emanalsayed2000@yahoo.com

1 Nutrition and Food Sciences Department, National Research Centre, El-Bohouth St. (Tahrir St.Prev.), Dokki 12622, Cairo, Egypt

2 Environmental and Occupational Medicine Department, National Research Centre, El-Bohouth St. (Tahrir St.Prev.), Dokki 12622, Cairo, Egypt also multiple vital organ failure such as renal and hepatic failure. This unexpected pandemic was caused by a newly discovered severe acute respiratory syndrome coronavirus-2 (SARS-COV-2). It has a rapid transmission that occurs mainly through respiratory droplets and oral routes. The virus RNA has also been detected in the gastrointestinal tract where the virus can invade enterocytes [1].

Coronavirus disease 2019 is distinguished by immune system activation with concomitant inflammation [2], hypercoagulation, hyperferritinemia, and decreased hemoglobin levels indicating anemia [3, 4]. It was documented that both anemia and hyperferritinemia are strong predictors of mortality [5]. In this context, Taneri et al. [4] reported that disturbance of iron metabolism and anemia may play a critical role in multiple organ dysfunctions in COVID-19 patients. Hepcidin is the master regulator of iron homeostasis. It is worth noting that a large number of activating inputs must be integrated to tightly regulate hepcidin gene expression 
during inflammatory responses to ameliorate anemia of inflammation and make appropriate iron level adjustments [6]. Strategies based on hygiene and social distancing could not stop the rapid progression of the COVID-19 infection. An effective drug therapy is still development and vaccines, mostly of RNA type directed against the viral spike protein, are registered but not available in poor countries so that only $<50 \%$ of the world population are vaccinated (January 2022). Nutritional researchers have documented the use of functional foods or nutraceuticals as an adjuvant with conventional medicine or as preventive strategies to combat this pandemic [7, 8]. Herein, probiotics can facilitate the prevention or as adjuvant against COVID-19 [9]. Probiotics exhibit an immunomodulatory role in the cytokine storm associated with SARS-COV2 infection [10]. Furthermore, they can restore iron homeostasis that has been disrupted by viral infection [6]. Several studies have been conducted to demonstrate that probiotic administration reduces the risk of viral respiratory infection and decreases the severity of disease in patients [11]. Also, lower flu periods and reduced fever days were observed in individuals who were given Lactobacillus and Bifidobacterium strains [12]. In this narrative review, we summarized some aspects of SARS-COV2 pathophysiology, focusing on its effect on iron homeostasis and inflammation. Also, we attempted to discuss the role of probiotic supplementation in ameliorating such detrimental aspects based on the available literature.

\section{COVID-virus}

Viral respiratory infections are the major cause of worldwide mortality. The most important viruses in this respect are adenovirus, rhinovirus, influenza viruses, and coronavirus. The clinical symptoms of these viruses are closely similar including fever, cough, rhinitis, bronchitis, and fatigue. These symptoms range from mild to severe and the infection may involve the upper, middle, or lower respiratory tract [13]. Coronavirus (COVs) are the most pathogenic ones. COVs are highly diverse enveloped single-strand ribonucleic acid (RNA) with a positive-sense RNA genome [14]. COVs are classified as alpha, beta, gamma, and delta. Only alpha and beta COVs may cross animal and human barriers, causing respiratory, enteric, hepatic, or neurological infections [15].

In China, a new type form of COVs was discovered in 2019, causing severe pneumonia and multiple deaths. It is termed Severe Acute Respiratory Syndrome coronavirus-2 (SARS-COV-2). It belongs to Nidovirales order, coronaviridea family, coronaviridea subfamily, and beta cronavirus genus [16]. It is the cause of the current pandemic COVID19 which is rapidly spreading around the world due to person-to-person transmission [17].
Severe Acute Respiratory Syndrome coronavirus-2 possesses three main structural proteins in the virion envelope; spike protein(S), which aids virus adherences and fusion, membrane protein $(\mathrm{M})$, which participates in virion assembly, and envelope protein (E). Spikes are projections on the virus surfaces which appeared as crown-shaped and thus they are termed coronavirus. Furthermore, the virus contains nucleocapsid protein $(\mathrm{N})$ which is surrounded by an envelope [10]. Figure 1 depicts the structure of the SARSCOV2 virus [18].

Severe Acute Respiratory Syndrome coronavirus-2 enters the cells through binding by spikes (S1, S2) to angiotensinconverting enzymes 2 (ACE2) receptors. ACE-2, an aminopeptidase that is expressed in the lung cells, vascular endothelial cells, and macrophages [19]. The virus invades the host respiratory and gastrointestinal tracts. The S1 spikes exert a strong adhesion to the host cells while S2 spikes change cells surfaces to enable virus genome transfer into the host cells [20]. Then the virus RNA replicates in the host cells. Finally, new virus particles are formed and released into the blood or lymph streams and the cycle can start again. After an incubation period from 2 to 14 days, infection symptoms appear; the severity of symptoms is determined by host immunity; COVID-19 respiratory symptoms include fever, cough, dyspnea, and in some patients pneumonia [21]. In addition to respiratory symptoms, patients may exhibit gastrointestinal symptoms like diarrhea, vomiting, loss of appetite, and abdominal pain. This suggests that the virus can multiply in both the digestive and respiratory systems [22] and it also indicates the presence of the possibility of oral transmission by the respiratory droplets from the infected person. Furthermore, coronavirus has caused complications in renal and hepatic functions, cardiac activities; thrombotic

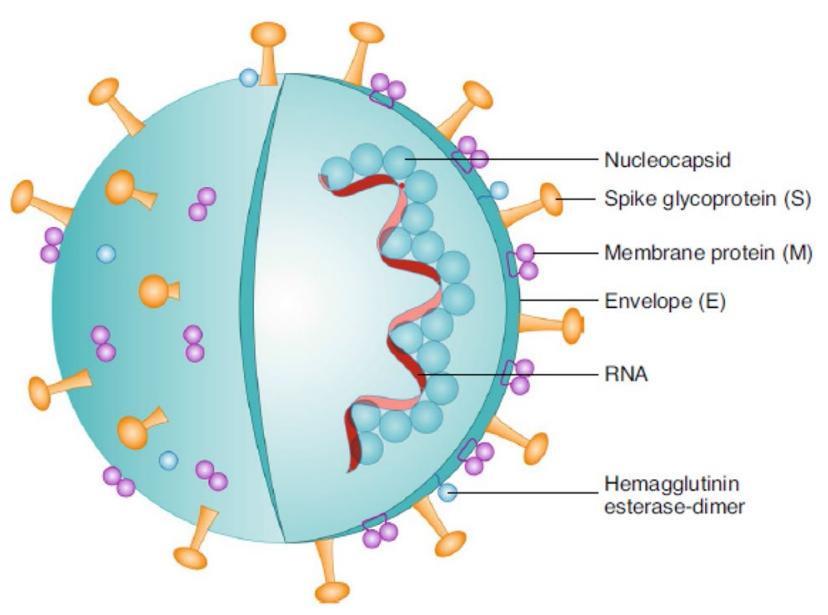

Fig. 1 SARS-CoV-2 structural diagram. This is an enveloped, positive-sense RNA virus with four major structural proteins: spike (S) and membrane (M) glycoproteins, as well as envelope (E) and nucleocapsid $(\mathrm{N})$ proteins, adapted from Florindo et al. [18] 
mechanism, diabetic control, nervous system, vision, and skin integrity [23].

\section{Immune response to SARS-COV-2}

After coronavirus enters human epithelial cells of respiratory and gastrointestinal systems or the conjunctiva, mucosal immunoglobulin A (IgA) presumably defends these epithelial tissues. An elevation of IgA titter was found in severe cases of COVID-19 [24]. Moreover, the IgA response appears to be more persistent and stronger than the immunoglobulin M (IgM) response [25]. Furthermore, the sentinel immature dendritic cells (DC) scavenge the viral antigens (phagocytosis). Meanwhile, the immature DC presents viral antigen to T-lymphocytes in the mucus epithelium and lymphoid tissue. Also, interferon type 1 (IFN-1) include IFN- $\alpha$ and IFN- $\beta$ up-regulate the expression of specific genes that inhibit viral replication and dissemination, resulting in viral RNA destruction [26]. However delayed IFN-1 production may activate the recruitment of inflammatory cells like macrophages, neutrophils, and monocytes. They secrete pro-inflammatory cytokines (such as IL-2, IL-6, IL-17, granulocyte-macrophage stimulating factor (GM.CSF), and TNF- $\alpha$ ) that cause a cytokine storm which results in immune exhaustion, tissue damage, and poor therapeutic outcomes [27]. In severe COVID-19 patients, an elevation of Interleukin-6 (IL-6) has been observed [28]. Also, high infiltrations of macrophages in the bronchi of dead COVID-19 individuals were observed by autopsy [29] and in the spleen and lymph nodes in COVID patients. These macrophages cause inflammation by producing an excessive amount of IL-6 [30]. In addition to inflammation caused by macrophages, they accumulate at the site of infection (lung) and stimulate fibroblasts causing pulmonary fibrosis. It is worth noting that the increased and uncontrolled pro-inflammatory cytokines secreted by innate immune cells strongly amplify the secretion of chemoattractant factors such as interleukin-8 (IL-8), and vascular endothelial growth factor (VEGF). Meanwhile, E-cadherin secretion is markedly reduced. Such changes contribute to vascular permeability and leakage which lead to pulmonary dysfunction and multiple organ failure [31]. Therefore it is suggested that inhibiting cytokine production may be a therapeutic approach for COVID-19. Recently, some drugs act to inhibit cytokine production and achieve good outcomes in COVID-19 patients [32].

Furthermore, the activation of macrophages, elevated numbers of monocytes, dendritic cells, and neutrophils were detected in COVID-19 patients [33, 34]. A bad prognosis is associated with a high neutrophil to lymphocyte ratio. Meanwhile, a significant decrease of natural killer cells (NK) in severe COVID-19 was documented due to the upregulation of NKG2A [35]. T lymphocytes regulate cellmediated immunity; while humoral immunity is regulated by B lymphocytes. Following viral infection, its peptides are loaded on epithelial cells or monocytes or dendritic cells where they are recognized by cytotoxic $\mathrm{T}$ lymphocytes (CD8) that kill them via apoptosis. Also, the secreted viral proteins are recognized by $\mathrm{CD} 4 \mathrm{~T}$ cells that produce interleukin-2 (IL-2) and IL-6 which cause the proliferation of B cells. Then, the B cells produce antibodies immunoglobulin $\operatorname{IgM}, \operatorname{IgG}$, and $\operatorname{IgA}$ which neutralize the virus [36]. This process of antibody secretion against COVID-19 takes about 19 days after symptoms appear [37]. It has been reported that in mild cases of COVID-19, patients had normal or higher CD4 and CD8 cell counts [38]. While, in severe cases, lymphocyte count was significantly decreased with a drastic reduction of CD8 T cells count [39]. This could be explained by the expression of NKG2A in CD8 T cells by viral infection with concomitant functional exhaustion of these cytotoxic lymphocytes and disease progression [40]. Notably, SARS-COV-1 and SARS-COV-2 are immunologically different [41]. Also, it is worth noting that the lymph nodes and spleen in individuals who had COVID-19 were atrophic indicating cell degeneration by the virus. Taken together, there are two stages of immune responses during the COVID-infections. (i) The first stage is represented by the immune defense protective phase. (ii) The second one is characterized by significant inflammation [42]. Accordingly, some infected individuals are asymptomatic due to their immune response in the first stage. While others may have vagarious symptoms due to compromised immune systems and the ability of the virus to block the secretion of IFN-1 ( $\alpha$ and $\beta$ ) with concomitant uncontrolled viral proliferation [33]. As a result, we conclude that people with strong immunity (innate and adaptive) can easily overcome the viral infection, whereas those with weakened immune systems fail to do so. Figure 2 depicts the adaptive and innate immune responses to the Covid-19 virus.

\section{COVID-19 and iron interrelationship}

Iron is an essential micronutrient that plays an important role in various physiological processes. It is involved in transporting and storing oxygen as part of hemoglobin. It is also incorporated in erythrocyte formation, electron transfer, thyroxin hormone production, fatty acid metabolism, prostaglandin synthesis, and cellular and humoral immunity. After absorption and sharing of different metabolic pathways, excess iron is stored in hepatocytes and the cells of the reticuloendothelial system [43]. There are two major forms of iron sources; heme iron (ferrous, Fe II) that is present in animals, and non-heme iron (ferric, Fe III) mainly found in plants origin. The bioavailability of heme iron is about $30 \%$ while that non-heme iron is around $<8 \%$. Factors that enhance iron bioavailability from the diet include vitamin C, folic acid, histidine, L-cysteine, meat, copper, citric acid, 
Fig. 2 Adaptive and innate immune response against Covid-19 virus. GM.CSF: Granulocyte-macrophage stimulating factor, $T h$ : T-helper, $I L$ : interleukin, adopted from Hosseini et al.[27]

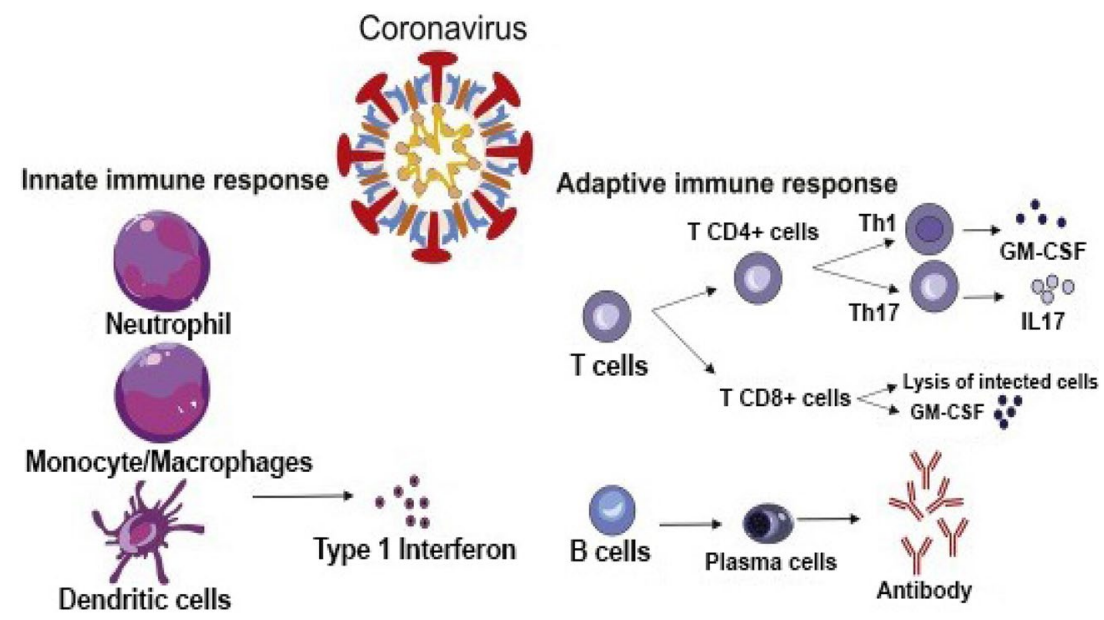

and lactic acid. On the other hand, phytates, oxalates, tannins, polyphenols, calcium, manganese, zinc, and phosphate reduce iron absorption and thus its bioavailability [44].

Until now, it has been unclear whether the disturbances in iron homeostasis are a reflection of physiological adaptation to infection or whether dysregulation of iron metabolism contributes to COVID-19 symptoms and outcomes [45]. Some patients with COVID-19 develop respiratory manifestations with preserved lung volume indicating hypoxia due to physiological disturbance other than alveolar dysfunction. This may be attributed to a disruption in iron metabolism [4]. In this context, evidence documented that COVID-19 patients exhibited decreased hemoglobin $(\mathrm{Hb})$ levels that indicate the presence of anemia [3]. Hb is one of the most important determinants of carrying oxygen in the blood. The decrease of $\mathrm{Hb}$ in patients, especially those with complications or chronic diseases suggests an inability of $\mathrm{Hb}$ to support the increased peripheral tissue needs for oxygen during infection which worsens the situation.

Severe Acute Respiratory Syndrome coronavirus-2 interacts with $\mathrm{Hb}$ molecules through CD 147, CD2b, and other receptors present mainly on erythrocytes and other hemoglobin cells resulting in $\mathrm{Hb}$ denaturation [46]. Consequently, functioning $\mathrm{Hb}$ concentration decreases and free toxic heme is released, resulting in tissue oxygen deprivation. Besides, the progressively reduced $\mathrm{Hb}$ concentration may lead to sideroblastic anemia with higher red cell distribution width (RDW) indicating excessive production of immature RBC. Some COVID-19 patients have increased levels of RDW suggesting increased mortality risk [47].

Hepcidin is a key regulator of iron homeostasis. It binds to ferroportin preventing iron release from cells. As a result, there is a drop in circulating iron. Therefore, Hepcidin controls the iron distribution and availability. There is a distant similarity between SARS-COV-2 spike protein and hepcidin that may enable the virus to bind to ferroportin receptors with concomitant cellular iron overload [48]. Thus the virus may have a direct action on iron levels by mimicking hepcidin. Another indirect mechanism is involved by the strong inflammation resulting from viral infection. A cytokine storm produced by SARS-COV-2 results from massive amounts of IL-6 expression which induces the production of hepcidin [49]. Moreover, such inflammation causes hyperferritinemia [50]. Ferritin is the most distinct cellular iron storage protein and an increased level may be indicative of severe inflammation, as well as its important impact on iron metabolism [51]. Pathologically high ferritin levels were found in critically ill COVID-19 patients [52]. It has been documented that hepcidin dysregulation and hyperferritinemia are markedly correlated to iron toxicity and multiple organ failure in COVID-19 patients [53] where increased intracellular iron induces iron-dependent peroxidation. Consequently, it causes cellular apoptosis, which is known as ferroptosis [54]. It is worth noting that iron dysmetabolism and ferroptosis have been linked to COVID-19-associated symptoms like cognitive impairment and anosmia [54]. Notably, both hyperferritinemia and increased hepcidin expression are still present in a relevant concentration in COVID-19 patients two months after the disease onset [55]. Strikingly, diabetes, obesity, and increased age elevate hepcidin levels and over-expression CD147 receptors with consequence rise of viral complications in those individuals [56]. Taken together, we can conclude that SAR-COV-2 may be an important detriment to iron dysmetabolism and anemia aggravates COVID-19 symptoms and leads to poor outcomes.

\section{The general view about probiotics}

Probiotics are live microorganisms (bacteria and yeasts) that when administered in sufficient quantities, may provide health benefits in addition to their basic role in nutrition [57]. These organisms are naturally present in food and water, also they can be added during food processing such as in cheese, 
sausages, yogurt, and other fermented milk products [58]. The majority of probiotics are from the genera Lactobacillus and Bifidobacterium. The potential roles of probiotics may include prevention and assisting in treatments of various diseases such as gastrointestinal infections, inflammatory bowel disease, lactose intolerance, urogenital infections, cancers, cystic fibrosis, dental caries, oral bad odors, and antibiotic side effects [7, 59]. Probiotics can also be used as an adjuvant with vaccines. An elevation of rotavirus-specific IgM was observed when children had taken Lactobacillus $G G$ as an adjuvant to rotavirus vaccine [60].

Moreover, certain strains of lactic acid bacteria can modulate both natural and acquired immunity when administered in an adjusted dose of at least $10^{9}$ colony forming units $(\mathrm{CFU}) /$ day since the immunomodulation of probiotics is dose-dependent [61]. Lactobacillus as johnsonii LA1 or Bifidobacterium lactis $B B-12$ enhance the phagocyte capacity of peripheral blood leukocytes [62]. Also, probiotic administration could show a significant increase in the expression of receptors involved in phagocytosis [61]. Increased activity of natural killer cells (NK cells) and phagocytosis of leukocytes of human volunteers consuming probiotic products were documented [63]. Furthermore, the humoral immunity to infections or immunization has been potentiated by lactic acid bacteria intake. Lactobacillus $G G$ administration increases $\operatorname{IgG}, \operatorname{Ig} \mathrm{A}$, and $\operatorname{IgM}$ and elevates $\operatorname{Ig} \mathrm{A}$ secretion against rotavirus more efficiently than Lactobacillus casei [64]. It has been shown that probiotics may increase IL-10, transforming growth factor-beta (TGF- $\beta$ ) and decrease tumor necrosis factor-alpha (TNF- $\alpha$ ) [65].

\section{Probiotics modulation of iron homeostasis in COVID-19}

In addition to the traditional factors that significantly reduce iron availability such as insufficient intake, pregnancy, rapid growth, bleeding, menstruation, etc. [66], COVID-19 induces iron deficiency to the point where iron deficiency anemia (IDA) may result [3]. The above-mentioned contributing mechanisms are involved in such induction. Therefore, many approaches could be used to modulate iron bioavailability with no or minimal adverse effects such as the use of functional foods like omega 3 fatty acids [67] and probiotics either alone or as adjunctive therapy with iron [68].

Multiple pieces of evidence have demonstrated that probiotics can improve iron bioavailability. The administration of probiotics in addition to dietary iron or as an adjuvant with iron supplements is one of the most important strategies for improving iron status and reducing the adverse effects of the supplement. In an animal study, the multispecies probiotic formula is given orally to rats in two dose levels $2.5 \times 10^{9} \mathrm{CFU} /$ day and $1 \times 10^{10} \mathrm{CFU} /$ day. Both administrations induce enhancement of iron bioavailability in a dose-independent manner [69]. Fermented milk was fortified with iron and lactobacillus acidophilus and given to anemic preschool children. Their RBCs and Hb levels were significantly elevated as compared to anemic children who drank iron-fortified milk without the probiotic [70]. Lactobacillus fermentation appears to improve iron absorption by producing lactic acid and other organic acids, which aid in iron bioavailability [71]. In agreement with Silva et al. [70], Sazawal et al. [72] gave children milk fortified with Bifidobacterium lactis HNO19 $(1.9 \times 107 \mathrm{CFU} /$ day $)$ for one year. They found that the probiotic-fortified milk reduced the number of iron-deficient children when compared to non-fortified milk. On the other hand, Lactobacillus reuteri DSM and Lactobacillus casei CRL $431\left(5 \times 10^{8} \mathrm{CFU} /\right.$ day $)$ fortified milk failed to increase iron status in anemic children [73]. This result may be attributed to the differences in dose level, duration of intake, and probiotic strains. However, a probiotic formulation containing Lactobacillus Plantarum $299 \mathrm{v}$, iron, and vitamin C [74] or $10^{10} \mathrm{CFU}$ freeze-dried Lactobacillus Plantarum 299v capsules taken with breakfast [71] to anemic women improved iron absorption and iron bioavailability. After four weeks of administration of Pediococcus acidilactici MTCC5101 and Bacillus coagulans MTCC492 to young anemic women hemoglobin values improved [75]. Probiotics may improve iron bioavailability through several mechanisms. Bacteria convert ellagic acid (EA) to urolithin acid (UA) which is unable to bind ferric ions $\left(\mathrm{Fe}^{3+}\right)$, and then it reduces $\mathrm{Fe}^{3+}$ to ferrous ions $\left(\mathrm{Fe}^{2}+\right)$ by p-hydroxyphenyl lactic acid which is excreted by bacteria and thus increases iron absorption [76]. Moreover, probiotics can selectively inhibit intestinal pathogenic microbiota and produce glutamine which helps to maintain intestinal mucosa integrity with concomitant improvement of iron absorption [77]. Furthermore, Patel et al. [78] documented that siderophore production by probiotics helps to chelate and to solubiliz iron in the ferric form and making it biologically available. Also, increased mucin production by the intestinal surface promotes enterocyte iron uptake [79]. Furthermore, probiotic immunomodulation has antiinflammatory effects [80], which suppress hepcidin, the major inhibitor of iron absorption [71]. Vonderheid et al. [6] and Rusu et al. [81] have also confirmed the relationship between probiotics and increased iron bioavailability. As a result, probiotics are being used as a part of the strategy to ameliorate anemic conditions in our population, especially in COVID-19 patients. Figure 3 shows the mechanisms by which probiotics improve iron bioavailability.

\section{Potential mechanisms of probiotic for combating COVID-19}

Probiotic administration can significantly boost individual immunity allowing the COVID virus to be defeated $[8$, 


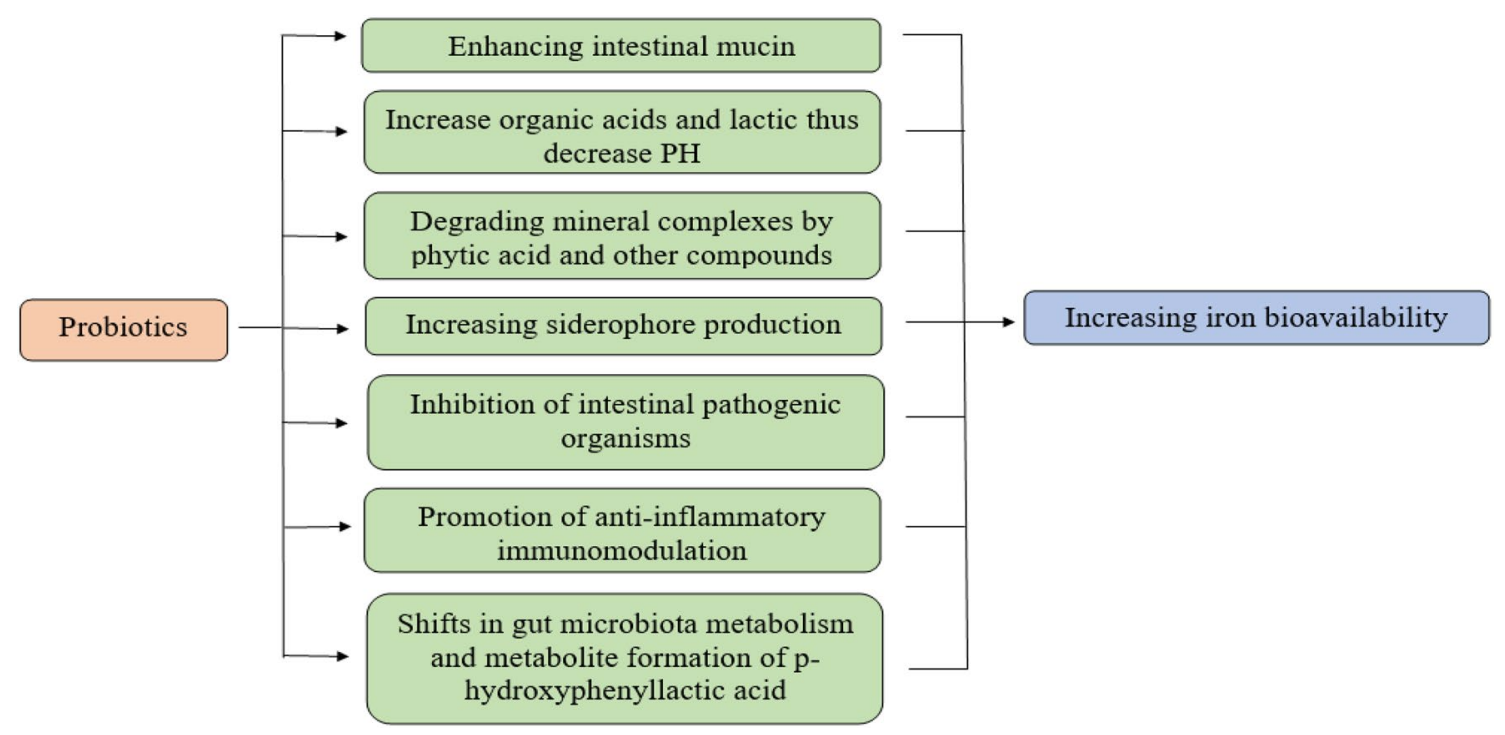

Fig. 3 Possible mechanisms involved in enhancement of iron bioavailability by probiotics during COVID-19

$10,82]$. Especially for elderly and immune-compromised patients, whose consortium of gut probiotics is low so they suffer from severe symptoms and are more susceptible to infection than normal subjects [83].

The respiratory tract is the primary site of SARS-COV-2 entry. The virus has a significant impact on the gastrointestinal system as well. This may be attributed to the virus's affinity for epithelial cells, in both systems that have the receptor angiotensin-converting enzyme-2 (ACE-2) [20]. Such a co-infection in the gut causes an imbalance between good and bad bacteria which is known as dysbiosis [84]. Strikingly, in SARS-COV-2 the intestinal microbiota exerts a significant bacterial diversity. Where, there is a higher number of pathogenic bacteria such as Streptococcus, Veillonella, Rothia, etc., and a lower number of Eubacterium ventriosum, and Lachnospiraceae. Indeed, there is an inverse relationship between high levels of these bacteria and a poor prognosis for COVID-19 [85]. Probiotics administration contributes to repopulating the gut with beneficial bacteria with concomitant reduction of pathogenic microbes' proliferation establishing a state of eubiosis instead of dysbiosis. Both Lactobacillus and Bifidobacterium are the most common probiotics that be used to balance a diverse intestinal ecosystem against COVID-19 [86]. Consequently, they can help restore the healthy gut-lung axis and reduce pathogens' translocation via the intestinal mucosa [87] thus preventing overlapping infections. It is worth noting that a wellbalanced gut community is critical for pulmonary immunity. Evidence suggests that dysbiosis influences lung dysfunction by altering the immune responses of neutrophils, inflammatory cytokines, different types of T- cells, and Toll-like receptors [88]. Also, it has been documented that probiotics exhibit anti-viral properties through alveolar macrophages, neutrophils, NK cells, and elevated levels of pro-inflammatory cytokines such as TNF- $\alpha$ and IL- 6 at the beginning of the infection (first phase) [89]. Some probiotic strains, such as Lactobacillus paracasei [90] have ACE-2 receptors that can compete with the host receptor and bind to the invading virus preventing or inhibiting pathogen-host cell receptor interaction [25]. Moreover, some probiotic strains can affect gene expression which may enhance antiviral activity, such as that in dendrites cells and enterocytes [91]. Lactobacillus strains regulate the expression of tight junction proteins thus collaborating to preserve the intestinal epithelial integrity and overcome pathogen invasion [92].

Purines are required for the synthesis of viral RNA. Therefore, reducing purine availability could slow virus replication and thus could control viral infection. Lactobacillus gasseri can be used as adjuvant therapy to reduce purine levels via metabolizing the purine nucleosides (inosine and guanosine) [93].

Probiotics produce short-chain fatty acids (SCFA) through fermentation that have an immunomodulatory function through their influence on the extracellular and intracellular molecules. They can bind to G-proteincoupled receptors and thus regulates immune function. Besides, they could initiate B-cell differentiation, antibody synthesis, as well as improve antibody-antigen interaction. Ji et al. [94] demonstrated that high levels of Corynebacterium and Lactobacillus species in the lung increase SCFA production, which leads to increased interferon $\beta$ production in alveolar macrophages. In this context, butyric acid secreted by probiotics was documented to enhance the integrity of tight junctions and they also act as fuel for colonocytes thus may reduce the SARSCOV-2 invasion [95]. Furthermore, lactic acid is an 
essential microbiocidal compound so that enables the host cells to prevent the virus from replicating. Interestingly, probiotic strains also produce essential amino acids like tryptophan, which attenuate TNF- $\alpha$, induce activation of NF-KB, reduce the pro-inflammatory cytokines, and fortify intestinal tight junctions [52]. Gamma-aminobutyric acid (GABA) production by Lactobacillus Brevis exhibits immune regulatory effects and induces autophagy in T-cells and NK cells. It also stimulates antigen-presenting cells [70]. The secretion of IgA is enhanced by probiotic administration [96]. IgA is important to mucosal barrier function. It also binds to pathogens renders them inactive, as well as optimizes DC action and overall immunological responses.

Lactobacillus Plantarum DR7 enhances the level of anti-inflammatory cytokines IL-4 and IL-10 and reduces lipid peroxidation and oxidative stress in a human study [97]. Consequently, they can modify the pro-inflammatory and immune regulatory cytokines to act against virus invasion and cytokines storms. Overall, probiotic administration can reduce inflammation, modulate immunity, improve interferon concentrations, increase the activities and number of NK cells, T cells, and antigen-presenting cells, and increase the levels of mucosal and systemic antibodies in the lung [98]. Figure 4 demonstrates the potential mechanisms by which probiotics could combat COVID-19.

\section{Safety of probiotics}

Probiotics are usually safe even in populations with comorbidities, such as those with chronic disease or immunecompromised individuals taking into consideration to use of the adjusted dose of high-quality probiotics [99]. When the dose is not appropriate in such critical cases, bacteremia or fungemia may be associated with probiotic administration. There are no contraindications to probiotics.

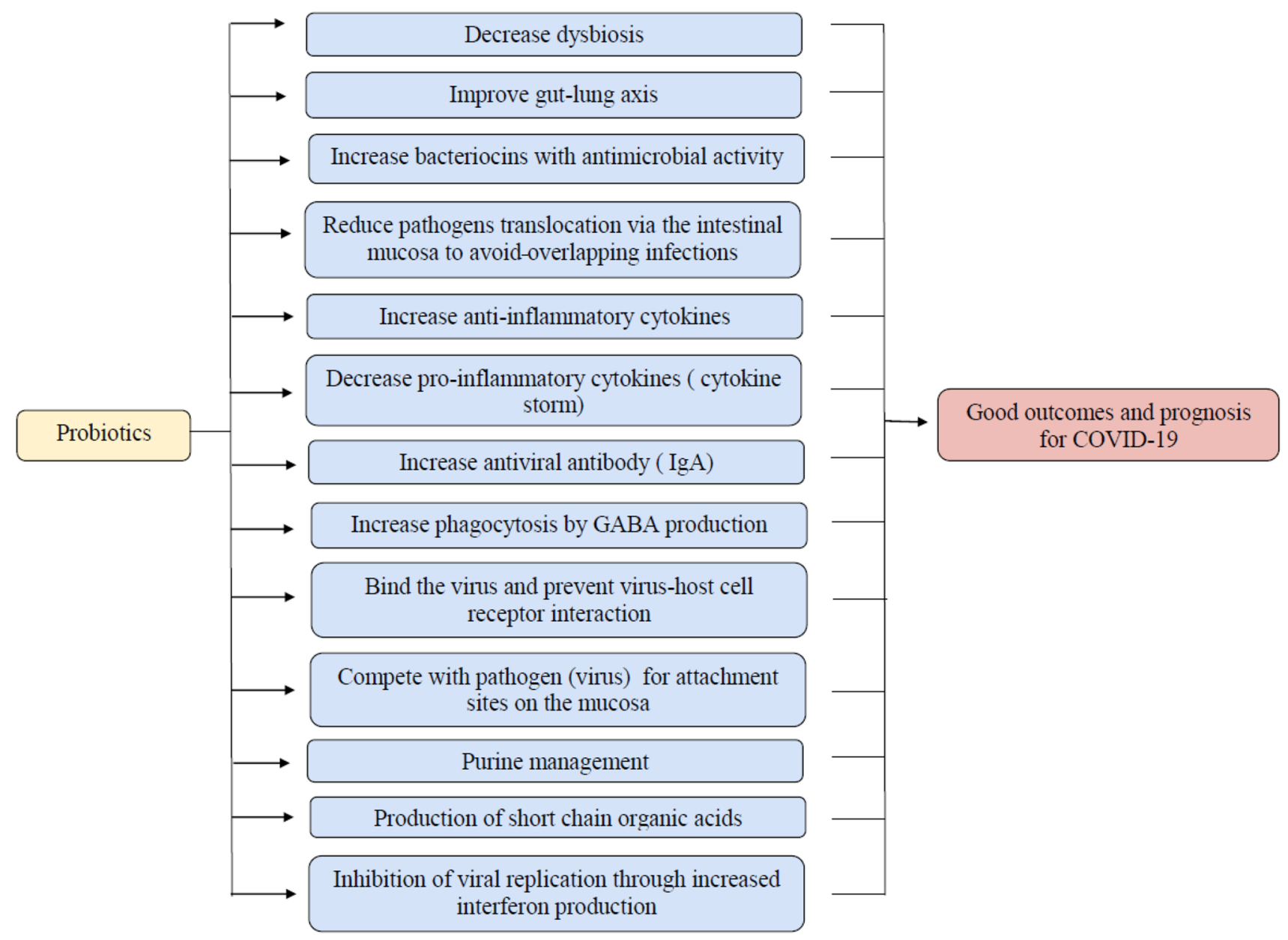

Fig. 4 A schematic representation of the possible mechanisms that probiotics may achieve against COVID-19 


\section{Conclusion}

COVID-19 is a pandemic disease until now with still increasing number of positive cases and deaths. Based on the available data, we can conclude that disturbed iron homeostasis and inflammation play a significant role in disease outcomes. A healthy hemoglobin system is required for functional oxygen uptake and transport. It is postulated that iron deficiency anemia, whether as a risk factor already present in individuals or resulting from COVID-19, seems to be associated with severe symptoms due to the reduction of oxygen supply to the tissue below the required level. Also, the resulting inflammation from a viral infection can be attributed to the activation of both innate and adaptive immunity. Many strategies have been implemented to combat this pandemic. SARS-COV-2 vaccines are widely available. However, the vaccination is not equally distributed over all countries, and the vaccination rate is insufficient to achieve herd immunity. Antiviral drugs are in advanced development. Covid-19 may be overcome through social measures such as improved health hygiene, medical masks, and social isolation with medical support. Using functional foods as adjunctive therapy with such approaches may be beneficial. By reviewing the current literature, it was found that probiotics can be a potential adjunct to ameliorate symptoms and improve the outcome of COVID-19. Probiotic supplementation significantly increases iron bioavailability and reduces inflammation. Many mechanisms could explain such probiotics' effects, particularly their immunomodulatory effects, their variable antiviral metabolites, and the correction of dysbiosis. Furthermore, some probiotic could directly prevent the virus from entering into the host cells as well as inhibit its replication. Therefore, a recommendation to use various probiotics as a co-therapy with the involved conventional approaches may be beneficial. At high quality and appropriate dosage no side effects are known. However, more pre-clinical studies and clinical trials are required to confirm the ameliorative effects of probiotics on COVID-19 symptoms and outcomes.

Author Contributions EME had an idea for the article. Both KSI and EME collected the data, wrote, edited, carefully revised the work, and final approved of the manuscript.

Funding This research did not receive any specific grant from funding agencies in the public, commercial, or nonprofit sectors.

\section{Declarations}

Conflict of interest The authors have no conflict of interest to declare.

Ethical Approval This article does not contain any studies with human participants or animals performed by any of the authors.
Consent to Publish Not applicable.

\section{References}

1. Lin L, Jiang X, Zhang Z et al (2020) Gastrointestinal symptoms of 95 cases with SARS-CoV-2 infection. Gut 69:997-1001

2. Mishra KP, Singh AK, Singh SB (2020) Hyperinflammation and immune response generation in COVID-19. NeuroImmunoModulation 27:80-86

3. Fan BE, Chong VCL, Chan SSW et al (2020) Hematologic parameters in patients with COVID-19 infection. Am J Hematol 95(6):E131-E134. https://doi.org/10.1002/ajh.25774

4. Taneri PE, Gómez-Ochoa SA, Llanaj E et al (2020) Anemia and iron metabolism in COVID-19: a systematic review and meta-analysis. Eur J Epidemiol 35(8):763-773

5. Liu Z, Sun R, Li J et al (2019) Relations of anemia with the all-cause mortality and cardiovascular mortality in general population: a meta-analysis. Am J Med Sci 358(3):191-199

6. Vonderheid SC, Tussing-Humphreys L, Park C et al (2019) A Systematic review and meta-analysis on the effects of probiotic species on iron absorption and iron status. Nutrients 11(12):2938. https://doi.org/10.3390/nu11122938

7. Stavropoulou E, Bezirtzoglou E (2020) Probiotics as a weapon in the fight against COVID-19. Front Nutr 7:614986. https:// doi.org/10.3389/fnut.2020.614986

8. Al-Ansari MM, Sahlah SA, AlHumaid L et al (2021) Probiotic lactobacilli: can be a remediating supplement for pandemic COVID-19. A review. J King Saud Univ Sci 33(2):101286. https://doi.org/10.1016/j.jksus.2020.101286

9. Gohil K, Samson R, Dastager S, Dharne M (2021) Probiotics in the prophylaxis of COVID-19: something is better than nothing. 3 Biotech 11(1):1. https://doi.org/10.1007/ s13205-020-02554-1

10. Zafar N, Aslam M, Ali A et al (2020) Probiotics: helpful for the prevention of COVID-19? Biomed Res Ther 7(11):4086-4099

11. Sencio V, Barthelemy A, Tavares LP et al (2020) Gut dysbiosis during influenza contributes to pulmonary pneumococcal superinfection through altered short-chain fatty acid production. Cell Rep 30(9):2934-2947

12. Pullano G, Pinotti F, Valdano E et al (2020) Novel coronavirus (2019-nCoV) early-stage importation risk to Europe, January 2020. Euro Surveill 25(4):2000057

13. Lysholm F, Wetterbom A, Lindau C et al (2012) Characterization of the viral microbiome in patients with severe lower respiratory tract infections, using metagenomic sequencing. PLoS ONE $7(2): \mathrm{e} 30875$

14. Zhu Z, Lian X, Su X et al (2020) From SARS and MERS to COVID-19: a brief summary and comparison of severe acute respiratory infections caused by three highly pathogenic human coronaviruses. Respir Res 21(1):224

15. Jiang F, Deng L, Zhang L et al (2020) Review of the clinical characteristics of coronavirus disease 2019 (COVID-19). J Gen Intern Med 35(5):1545-1549

16. Li X, Geng M, Peng Y et al (2020) Molecular immune pathogenesis and diagnosis of COVID-19. J Pharm Anal 10(2):102-108

17. Zhou P, Yang XL, Wang XG et al (2020) A pneumonia outbreak associated with a new coronavirus of probable bat origin. Nature 579(7798):270-273

18. Florindo HF, Kleiner R, Vaskovich-Koubi D et al (2020) Immune-mediated approaches against COVID-19. Nat Nanotechnol 15(8):630-645. https://doi.org/10.1038/s41565-020-0732-3 
19. Lake MA (2020) What we know so far: COVID-19 current clinical knowledge and research. Clin Med (Lond) 20(2):124-127. https://doi.org/10.7861/clinmed.2019-coron

20. Hoffmann M, Kleine-Weber H, Schroeder H et al (2020) SARSCoV-2 cell entry 384 depends on ACE2 and TMPRSS2 and is blocked by a clinically proven protease 385 inhibitor. Cell 181:271-280. https://doi.org/10.1016/j.cell.2020.02.052

21. Hamid S, Mir MY, Rohela GK (2020) Novel coronavirus disease (COVID-19): a pandemic (epidemiology, pathogenesis, and potential therapeutics). New Microbes New Infection 35:100679. https://doi.org/10.1016/j.nmni.2020.100679

22. Lamers MM, Beumer J, van der Vaart J et al (2020) SARSCoV-2 productively infects human gut enterocytes. Science 369(6499):50-54. https://doi.org/10.1126/science.abc1669

23. Gupta A, Madhavan MV, Sehgal K et al (2020) Extrapulmonary manifestations of COVID-19. Nat Med 26(7):1017-1032. https:// doi.org/10.1038/s41591-020-0968-3

24. Okba NMA, Müller MA, Li W et al (2020) Severe acute respiratory syndrome coronavirus 2-specific antibody responses in coronavirus disease 2019 patients. Emerg Infect Dis 26(7):14781488. https://doi.org/10.3201/eid2607.200841

25. Rizzo P, Vieceli Dalla Sega F, Fortini F et al (2020) COVID-19 in the heart and the lungs: could we "Notch" the inflammatory storm? Basic Res Cardiol 115(3):31. https://doi.org/10.1007/ s00395-020-0791-5

26. Sallard E, Lescure FX, Yazdanpanah Y et al (2020) Type 1 interferons as a potential treatment against COVID-19. Antiviral Res 178:104791. https://doi.org/10.1016/j.antiviral.2020.104791

27. Hosseini A, Hashemi V, Shomali N et al (2020) Innate and adaptive immune responses against coronavirus. Biomed Pharmacother 132:110859. https://doi.org/10.1016/j.biopha.2020.110859

28. Santa Cruz A, Mendes-Frias A, Oliveira AI et al (2021) Interleukin-6 is a biomarker for the development of fatal severe acute respiratory syndrome coronavirus 2 pneumonia. Front Immunol 12:613422. https://doi.org/10.3389/fimmu.2021.613422

29. Barton LM, Duval EJ, Stroberg E (2020) Covid-19 autopsies, Oklahoma, USA. Am J Clin Pathol 153:725-733. https://doi.org/ 10.1093/ajcp/aqaa062

30. Park MD (2020) Macrophages: a Trojan horse in COVID19? Nat Rev Immunol 20(6):351. https://doi.org/10.1038/ s41577-020-0317-2

31. Moore BJB, June CH (2020) Cytokine release syndrome in severe COVID-19. Science 368:473-474. https://doi.org/10. 1126/science.abb8925

32. Heimfarth L, Serafini MR, Martins-Filho PR et al (2020) Drug repurposing and cytokine management in response to COVID19: A review. Int Immunopharmacol 88:106947. https://doi.org/ 10.1016/j.intimp.2020.106947

33. Ye Q, Wang B, Mao J (2020) The pathogenesis and treatment of the 'Cytokine Storm' in COVID-19. J Infect 80(6):607-613. https://doi.org/10.1016/j.jinf.2020.03.037

34. Liu B, Han J, Cheng X et al (2020) Persistent SARS-CoV-2 presence is companied with defects in adaptive immune system in non-severe COVID-19 patients. medRxiv. 26:20044768. https:// doi.org/10.1101/2020.03.26.20044768

35. Zhang W, Zhao Y, Zhang F et al (2020) The use of anti-inflammatory drugs in the treatment of people with severe coronavirus disease 2019 (COVID-19) The perspectives of clinical immunologists from China. Clin Immunol 214:108393. https://doi.org/ 10.1016/j.clim.2020.108393

36. Yang D, Chu H, Hou Y et al (2020) Attenuated interferon and proinflammatory response in SARS-CoV-2-infected human dendritic cells is associated with viral antagonism of STAT1phosphorylation. J Infect Dis 222(5):734-745. https://doi.org/10. 1093/infdis/jiaa356
37. Long QX, Liu BZ, Deng HJ et al (2020) Antibody responses to SARS-CoV-2 in patients with COVID-19. Nat Med 26(6):845848. https://doi.org/10.1038/s41591-020-0897-1

38. Mahmoudi S, Yaghmaei B, Sharifzadeh Ekbatani M et al (2021) Effects of Coronavirus Disease 2019(COVID-19) on Peripheral Blood Lymphocytes and Their Subsets in Children: Imbalanced CD4+/CD8+TCell Ratio and Disease Severity. Front Pediatr 9:643299. https://doi.org/10.3389/fped.2021.643299

39. Zheng HY, Zhang M, Yang CX et al (2020) Elevated exhaustion levels and reduced functional diversity of T cells in peripheral blood may predict severe progression in COVID-19 patients. Cell Mol Immunol 17(5):541-543. https://doi.org/10.1038/ s41423-020-0401-3

40. Zheng M, Gao Y, Wang G et al (2020) Functional exhaustion of antiviral lymphocytes in COVID-19 patients. Cell Mol Immunol 17(5):533-535. https://doi.org/10.1038/s41423-020-0402-2

41. Ju B, Zhang Q, Ge J et al (2020) Human neutralizing antibodies elicited by SARS-CoV-2 infection. Nature 584(7819):115-119. https://doi.org/10.1038/s41586-020-2380-z

42. Shi Y, Wang Y, Shao C et al (2020) COVID-19 infection: the perspectives on immune responses. Cell Death Differ 27(5):14511454. https://doi.org/10.1038/s41418-020-0530-3

43. Chung J, Wessling-Resnick M (2003) Molecular mechanisms and regulation of iron transport. Crit Rev Clin Lab Sci 40:151-182. https://doi.org/10.1080/713609332

44. Hallberg L, Hulthén L (2000) Prediction of dietary iron absorption: an algorithm for calculating absorption and bioavailability of dietary iron. Am J Clin Nutr 71(5):1147-1160

45. Edeas M, Saleh J, Peyssonnaux C (2020) Iron: innocent bystander or vicious culprit in COVID-19 pathogenesis? Int J Infect Dis 97:303-305. https://doi.org/10.1016/j.ijid.2020.05.110

46. L Wenzhong L Hualan 2020 COVID-19 Attacks the 1-beta chain of hemoglobin and captures the porphyrin to inhibit human heme metabolism ChemRxiv Preprint https://doi.org/10.26434/chemr xiv.11938173.v8.

47. Foy BH, Carlson JT, Reinertsen E et al (2020) Association of red blood cell distribution width with mortality risk in hospitalized adults with SARS-CoV-2 Infection. JAMA Netw Open 3(9):e2022058. https://doi.org/10.1001/jamanetworkopen.2020. 22058

48. Ganz T, Nemeth E (2015) Iron homeostasis in host defence and inflammation. Nat Rev Immunol 15:500-510. https://doi.org/10. 1038/nri3863.Iron

49. Nemeth E, Rivera S, Gabayan V et al (2004) IL-6 mediates hypoferremia of inflammation by inducing the synthesis of the iron regulatory hormone hepcidin. J Clin Invest 113:1271-1276. https://doi.org/10.1172/JCI200420945

50. Mehta P, McAuley DF, Brown M et al (2020) COVID-19: consider cytokine storm syndromes and immunosuppression. Lancet 395(10229):1033-1034. https://doi.org/10.1016/S0140-6736(20) 30628-0

51. Kernan KF, Carcillo JA (2017) Hyperferritinemia and inflammation. Int Immunol 29(9):401-409. https://doi.org/10.1093/ intimm/dxx031

52. Chen M, Liu Y, Xiong S et al (2019) Dietary 1-tryptophan alleviated LPS-induced intestinal barrier injury by regulating tight junctions in a Caco-2 cell monolayer model. Food Funct 10(5):2390-2398. https://doi.org/10.1039/c9fo00123a

53. Phua J, Weng L, Ling L et al (2020) Intensive care management of coronavirus disease 2019 (COVID-19): challenges and recommendations. Lancet Respir Med 8:506-517. https://doi.org/10. 1016/S2213-2600(20)30161-2

54. Sun Y, Chen P, Zhai B et al (2020) The emerging role of ferroptosis in inflammation. Biomed Pharmacother 1277:110108. https://doi.org/10.1016/j.biopha.2020.110108 
55. Sonnweber T, Boehm A, Sahanic S et al (2020) Persisting alterations of iron homeostasis in COVID-19 are associated with nonresolving lung pathologies and poor patients' performance: a prospective observational cohort study. Respir Res 21(1):276. https://doi.org/10.1186/s12931-020-01546-2

56. Cavezzi A, Troiani E, Corrao S (2020) COVID-19: hemoglobin, iron, and hypoxia beyond inflammation. A narrative review Clin Pract 10(2):1271. https://doi.org/10.4081/cp.2020.1271

57. FAO/WHO (Food and Agricultural Organization of the United Nations and World Health Organization) (2001) Health and nutritional properties of probiotics in food including powder milk with live lactic acid bacteria. World Health Organization [online], http://www.who.int/foodsafety/publications/fs_manag ement/en/probiotics.pdf.

58. Parvez S, Malik KA, Ah Kang S et al (2006) Probiotics and their fermented food products are beneficial for health. J Appl Microbiol 100:1171-1185

59. Faujdar SS, Mehrish P, Bishnoi S, Sharma A (2016) Role of probiotics in human health and disease: An update. Int J Curr Microbiol Appl Sci 5(3):328-344

60. Isolauri E, Joensuu J, Suomalainen H et al (1995) Improved immunogenicity of oral $\mathrm{D} \times \mathrm{RRV}$ reassortant rotavirus vaccine by Lactobacillus casei GG. Vaccine 13(3):310-312

61. Fang H, Elina T, Heikki A, Seppo S (2000) Modulation of humoral immune response through probiotic intake. FEMS mmunol Med Microbiol 29(1):47-52. https://doi.org/10.1111/j. 1574-695X.2000.tb01504.X

62. Schiffrin EJ, Rochat F, Link-Amster H et al (1995) Immunomodulation of human blood cells following the ingestion of lactic acid bacteria. J Dairy Sci 78(3):491-497. https://doi.org/10.3168/ jds.S0022-0302(95)76659-0

63. Gill HS, Rutherfurd KJ, Cross ML, Gopal PK (2001) Enhancement of immunity in the elderly by dietary supplementation with the probiotic Bifidobacterium lactis HNO19. Am J Clin Nutr 74:833-839

64. Majamaa H, Isolauri E, Saxelin M, Vesikari T (1995) Lactic acid bacteria in the treatment of acute rotavirus gastroenteritis. J Pediat Gastroenterol Nutr 20(3):333-338. https://doi.org/10. 1097/00005176-199504000-00012

65. Kumar A, Vandana, (2013) Probiotics: Nature's medicine. Int J Nutr Pharmacol Neurol Dis 3:219-228. https://doi.org/10.4103/ 2231-0738.114838

66. Abbaspour N, Hurrell R, Kelishadi R (2014) Review on iron and its importance for human health. J Res Med Sci 19:164-174

67. Kaur N, Chugh V, Gupta AK (2014) Essential fatty acids as functional components of foods- a review. J Food Sci Technol 51(10):2289-2303. https://doi.org/10.1007/s13197-012-0677-0

68. Adiki SK, Perla CK, Saha G et al (2019) Enhancement in iron absorption on intake of chemometrically optimized ratio of probiotic strain lactobacillus plantarum 299v with Iron supplement pearl millet. Biol Trace Elem Res 190(1):150-156. https://doi. org/10.1007/s12011-018-1541

69. Skrypnik K, Bogdański P, Schmidt M, Suliburska J (2019) The effect of multispecies probiotic supplementation on iron status in rats. Biol Trace Elem Res 192(2):234-243. https://doi.org/10. 1007/s12011-019-1658-1

70. Silva MR, Dias G, Ferreira CL et al (2008) Growth of preschool children was improved when fed an iron-fortified fermented milk beverage supplemented with Lactobacillus acidophilus. Nutr Res 28(4):226-232. https://doi.org/10.1016/j.nutres.2008.02.002

71. Hoppe M, Önning G, Hulthén L (2017) Freeze-dried Lactobacillus plantarum $299 \mathrm{v}$ increases iron absorption in young femalesDouble isotope sequential single-blind studies in menstruating women. PLoS ONE 12(12):e0189141. https://doi.org/10.1371/ journal.pone. 0189141
72. Sazawal S, Dhingra U, Hiremath G et al (2010) Effects of Bifidobacterium lactis HN019 and prebiotic oligosaccharide added to milk on iron status, anemia, and growth among children 1 to 4 years old. J Pediatr Gastroenterol Nutr 51(3):341-346. https:// doi.org/10.1097/MPG.0b013e3181d98e45

73. Agustina R, Bovee-Oudenhoven IM, Lukito W et al (2013) Probiotics Lactobacillus reuteri DSM 17938 and Lactobacillus casei CRL 431 modestly increase growth, but not iron and zinc status, among Indonesian children aged 1-6 years. J Nutr 143(7):11841193. https://doi.org/10.3945/jn.112.166397

74. Korčok DJ, Tršić-Milanović NA, Ivanović ND, Đorđević BI (2018) Development of probiotic formulation for the treatment of iron deficiency anemia. Chem Pharm Bull (Tokyo) 66(4):347352. https://doi.org/10.1248/cpb.c17-00634

75. Balgir PP, Kaur B, Kaur T (2014) A Preliminary clinical evaluation of probiotics Pediococcus acidilactici MTCC5101 and Bacillus Coagulans MTCC492 on young anemic women. Int J Fermented Foods 3(1):45-59

76. González A, Gálvez N, Martín J et al (2017) Identification of the key excreted molecule by Lactobacillus fermentum related to host iron absorption. Food Chem 228:374-380. https://doi.org/ 10.1016/j.foodchem.2017.02.008

77. Seo G, Shimizu K, Sasatsu M, Kono M (1989) Inhibition of growth of some enteropathogenic strain in mixed cultures of Streptococcus faecalis and Clostridium butyricum. Microbios Letter 40:151-160

78. Patel AK, Deshattiwar MK, Chaudhari BL, Chincholkar SB (2009) Production, purification and chemical characterization of the catecholate siderophore from potent probiotic strains of Bacillus spp. Bioresource Technol 100:368-373. https://doi.org/ 10.1016/j.biortech.2008.05.008

79. Mack DR, Ahrne S, Hyde L et al (2003) Extracellular MUC3 mucin secretion follows adherence of lactobacillus strains to intestinal epithelial cells in vitro. Gut 52(6):827-833. https:// doi.org/10.1136/gut.52.6.827

80. Wells JM (2011) Immunomodulatory mechanisms of lactobacilli. Microb Cell Fact 10((Suppl. S1)):S17. https://doi.org/10.1186/ 1475-2859-10-S1-S17

81. Rusu IG, Suharoschi R, Vodnar DC et al (2020) Iron supplementation influence on the gut microbiota and probiotic intake effect in iron deficiency-A literature-based review. Nutrients 12(7):1993. https://doi.org/10.3390/nu12071993

82. Baud D, Dimopoulou Agri V, Gibson GR et al (2020) Using probiotics to flatten the curve of coronavirus disease COVID-2019 pandemic. Public Health Front 8:186. https://doi.org/10.3389/ fpubh.2020.00186

83. Viana SD, Nunes S, Reis F (2020) ACE2 imbalance as a key player for the poor outcomes in COVID-19 patients with agerelated comorbidities - role of gut microbiota dysbiosis. Ageing Res Rev 62:101123. https://doi.org/10.1016/j.arr.2020.101123

84. Trottein F, Sokol H (2020) Potential causes and consequences of gastrointestinal disorders during a SARS-CoV-2 infection. Cell Rep 32(3):107915. https://doi.org/10.1016/j.celrep.2020.107915

85. Zuo T, Zhang F, Lui GCY et al (2020) Alterations in gut microbiota of patients with COVID-19 during time of hospitalization. Gastroenterol 159(3):944-955.e8. https://doi.org/10.1053/j.gastro.2020.05.048

86. Santacroce L, Inchingolo F, Topi S et al (2021) Potential beneficial role of probiotics on the outcome of COVID-19 patients: an evolving perspective. Diabetes Metab Syndr 15(1):295-301. https://doi.org/10.1016/j.dsx.2020.12.040

87. George Kerry R, Patra JK, Gouda S et al (2018) Benefaction of probiotics for human health: a review. J Food Drug Anal 26:927-939 
88. Wang H, Lian P, Niu X et al (2018) TLR4 deficiency reduces pulmonary resistance to Streptococcus pneumoniae in gut microbiota-disrupted mice. PLoS ONE 13:e0209183. https://doi.org/ 10.1371/journal.pone.0209183

89. Dumas A, Bernard L, Poquet Y et al (2018) The role of the lung microbiota and the gut-lung axis in respiratory infectious diseases. Cell Microbiol 20(12):e12966. https://doi.org/10.1111/ cmi. 12966

90. Verma A, Xu K, Du T et al (2019) Expression of human ACE2 in lactobacillus and beneficial effects in diabetic retinopathy in mice. Mol Ther Methods Clin Dev 14:161-170. https://doi.org/ 10.1016/j.omtm.2019.06.007

91. Zhang CX, Wang HY, Chen TX (2019) Interactions between intestinal microflora/probiotics and the immune system. BioMed Res Int 2019:6764919. https://doi.org/10.1155/2019/6764919

92. Caballero-Franco C, Keller K, De Simone C, Chadee K (2007) The VSL\#3 probiotic formula induces mucin gene expression and secretion in colonic epithelial cells. Am J Physiol Gastrointest Liver Physiol 292(1):G315-G322. https://doi.org/10.1152/ ajpgi.00265.2006

93. Morais AHA, Passos TS, Maciel BLL, da Silva-Maia JK (2020) Can probiotics and diet promote beneficial immune modulation and purine control in coronavirus infection? Nutrients 12(6):1737. https://doi.org/10.3390/nu12061737

94. Ji JJ, Sun QM, Nie DY et al (2021) Probiotics protect against RSV infection by modulating the microbiota-alveolar-macrophage axis. Acta Pharmacol Sin 42(10):1630-1641. https:// doi.org/10.1038/s41401-020-00573-5

95. Grilli E, Tugnoli B, Foerster CJ, Piva A (2016) Butyrate modulates inflammatory cytokines and tight junctions components along the gut of weaned pigs. Anim Sci J 94(3):433-436. https:// doi.org/10.2527/jas.2015-9787

96. Lemme-Dumit JM, Polti MA, Perdigón G, Galdeano CM (2018) Probiotic bacteria cell walls stimulate the activity of the intestinal epithelial cells and macrophage functionality. Benef Microbes 9(1):153-164. https://doi.org/10.3920/BM2016.0220

97. Di Pierro F (2020) A possible probiotic (S. salivarius K12) approach to improve oral and lung microbiotas and raise defenses against SAR S-CoV-2. Minerva Med 111(3):281-283. https:// doi.org/10.23736/S0026-4806.20.06570-2

98. Namba K, Hatano M, Yaeshima T, Takase M, Suzuki K (2010) Effects of Bifidobacterium longum BB536 administration on influenza infection, influenza vaccine antibody titer, and cellmediated immunity in the elderly. Biosci Biotechnol Biochem 74(5):939-945. https://doi.org/10.1271/bbb.90749

99. Sanders ME, Merenstein DJ, Ouwehand AC et al (2016) Probiotic use in at-risk populations. J Am Pharm Assoc 56(6):680686. https://doi.org/10.1016/j.japh.2016.07.001

100. Bajić SS, Đokić J, Dinić M et al (2020) GABA potentiate the immunoregulatory effects of Lactobacillus brevis BGZLS10-17 via ATG5-dependent autophagy in vitro. Sci Rep 10(1):1347. https://doi.org/10.1038/s41598-020-58177-2

Publisher's Note Springer Nature remains neutral with regard to jurisdictional claims in published maps and institutional affiliations. 